\title{
Isolation and Characterization of Secretory Granules Storing a Vasoactive Intestinal Polypeptide-Like Peptide in Torpedo Cholinergic Electromotor Neurones
}

\author{
Denes V. Agoston, Gordon H. C. Dowe, and Victor P. Whittaker \\ Arbeitsgruppe Neurochemie, Max-Planck-Institut für biophysikalische Chemie, Göttingen, F.R.G.
}

\begin{abstract}
Previous immunocytochemical work showed that the cholinergic electromotor neurones of Torpedo marmorata contain a vasoactive intestinal polypeptide-like immunoreactivity (VIPLI) that is conveyed to the terminals by axonal transport from the cell bodies where it is presumably synthesized. In extension of this work, we have now succeeded in isolating the VIPLI storage granules from both the terminals and the axons of these neurones and characterizing them morphologically and biochemically. They were readily separated from synaptic vesicles but contained several components in common that had previously been regarded as specific for synaptic vesicles. Among these were a heparan sulphate type of proteoglycan, synaptophysin, and a $\mathrm{Mg}^{2+}$ dependent ATPase. The VIPLI concentration in lobe tissue and the amount of tissue available were both insufficient to permit the isolation of granules from the electromotor cell
\end{abstract}

bodies by the same technique but it was possible to establish the presence of such granules by particle-exclusion chromatography, using the stable markers mentioned above. In contrast to the VIPLI-containing granules, axonal synaptic vesicles differed from their terminal counterparts in having a very low acetylcholine content relative to stable vesicle markers: they presumably fill up on reaching the terminal where they are exposed to higher concentrations of cytoplasmic acetylcholine. Key Words: Granules-Vasoactive intestinal polypeptide-like immunoreactivity--Electromotor neurones-Torpedo marmorata. Agoston D. V. et al. Isolation and characterization of secretory granules storing a vasoactive intestinal polypeptide-like peptide in Torpedo cholinergic electromotor neurones. J. Neurochem. 52, 17291740 (1989).
In a previous article (Agoston and Conlon, 1986), vasoactive intestinal polypeptide (VIP)-like immunoreactivity (VIPLI) was detected in the cell bodies, axons, and nerve terminals of the electromotor neurones of Torpedo marmorata. Ligation experiments showed that the neuropeptide was being supplied to the terminals in the electric organs by anterograde axonal transport from the electromotor cell bodies in the electric lobes.

The presence of a VIP-like peptide in electromotor neurones is of particular interest because it demonstrates that this extensively used model cholinergic system displays with many other central and peripheral cholinergic systems the phenomenon of the colocalization of a neuropeptide with a "classical," small-mo- lecular-mass neurotransmitter. The evidence for this in general is so far mainly immunocytochemical, but recently it was shown that VIP copurifies with choline acetyltransferase and another cholinergic marker, Chol1 , when the cholinergic subpopulation of rat brain synaptosomes is isolated by immunoadsorption (Agoston et al., 1988a). It was calculated that $75 \%$ of rat cortical VIP was localized in the cholinergic subpopulation.

Other recent work, especially with the myenteric plexus of guinea-pig ileum (Agoston et al., 1988b), has shown that the intracellular dynamics of acetylcholine and VIP release are quite different. They are consistent with the storage of the classical transmitter mainly in small synaptic vesicles that are preferentially discharged
Received May 13, 1988; revised manuscript received October 13, 1988; accepted October 27, 1988.

Address correspondence and reprint requests to Dr. V.P. Whittaker at AG Neurochemie, MPI für biophysikalische Chemie, Postfach 2841, D-3400 Göttingen, F.R.G.

The present address of Dr. D. V. Agoston is Laboratory of Cell Biology, National Institute of Mental Health, Bldg. 36, Rm. 3A17, Bethesda, MD 20892, U.S.A.
Abbreviations used: ChAT, choline acetyltransferase; fmol-eq, femtomole equivalents; LDH, lactate dehydrogenase; PMSF, phenylmethylsulphonyl fluoride; SDS-PAGE, sodium dodecyl sulphatepolyacrylamide gel electrophoresis; SV-eq, synaptic vesicle equivalents; TPPase, thiamine pyrophosphatase; VIP, vasoactive intestinal polypeptide; VIPLI, vasoactive intestinal polypeptide-like immunoreactivity. 
at low frequencies of stimulation and recycle in the terminal, taking up and discharging transmitter newly synthesized in the terminal cytoplasm, and with the storage of the neuropeptide in larger, dense-cored granules that are preferentially discharged during highfrequency stimulation and cannot be recycled in the periphery.

As a further contribution to an understanding of the phenomenon of colocalization, we have now undertaken the isolation of the organelles storing the electromotor form of VIP and have compared them with the now well-characterized acetylcholine-rich synaptic vesicles (Whittaker, 1984). For this purpose, use was made of two putative stable synaptic vesicle markers, vesicular proteoglycan (Agoston et al., 1986 and references therein) and synaptophysin (also known as p38), a transmembrane glycoprotein of unknown function found in synaptic vesicles (Jahn et al., 1985; Wiedenmann and Franke, 1985). A preliminary account of this work has been given (Agoston, 1987).

\section{MATERIALS AND METHODS}

\section{Preparation of subcellular fractions}

Tissues. Electric organs, electromotor nerves, and electric lobes were removed from adult Torpedo of either sex under Tricaine anaesthesia, induced by immersing the fish in sea water containing $0.05 \%$ Tricaine methanesulphonate (Sandoz MS 222 supplied by Sigma, Deisenhofen, F.R.G.). The freshly dissected electric organs and electromotor nerves were frozen and stored in liquid nitrogen until used; the electric lobes were used immediately. Electric organs and lobes were removed from fish transported to Göttingen from the Station Biologique d'Arcachon and kept for at least 1 week before use in tanks of aerated and filtered artificial sea water at 15$17^{\circ} \mathrm{C}$; nerves were collected in Arcachon in early surnmer from 75 freshly caught fish.

Solutions. All sucrose or sucrose- $\mathrm{NaCl}$ solutions used in the extraction and subcellular fractionation of tissues were 820 mosmoles or more and contained, in addition, $10 \mathrm{mM}$ HEPES buffer, $\mathrm{pH} 6.8 ; 3 \mathrm{~m} M$ EGTA; $1 \mathrm{~m} M$ EDTA; the cathepsin inhibitor phenylmethylsulphonyl fluoride (PMSF) $(0.1 \mathrm{~m} M)$; and the kallikrein inhibitor aprotinin (Trasylol, Bayer, 100 inhibitory units $\mathrm{ml}^{-1}$ ) and in some experiments, $0.01 \%$ thiomersal and $0.05 \%$ bacitracin; $\mathrm{pH}$ values given are those at $0^{\circ} \mathrm{C}$. The addition of the protease inhibitors was considered advisable in view of the high protease activity of electric organ (Turner et al., 1987), but even so, recoveries of VIPLI tended to be lower after tissue fractionation than those of other components.

Comminution and extraction of electric organs and electromotor nerves. Frozen tissue was comminuted and extracted essentially as described by Ohsawa et al. (1979) except that in the case of electric organ a larger (1.8:1) tissue-to-saline $(0.935 \mathrm{M} \mathrm{NaCl}$ ) ratio was used. For a single zonal run (see below) typically $70-80 \mathrm{~g}$ of frozen electric organ and $30-40$ $\mathrm{g}$ of frozen nerves were used.

Fractionation of tissue extracts. The extracts were centrifuged at $10,000 \mathrm{rpm}$ for $30 \mathrm{~min}$ to remove coarse cell debris and the supernatants $(30 \mathrm{ml}$ corresponding to $54 \mathrm{~g}$ of electric organ or $25 \mathrm{ml}$ corresponding to $25 \mathrm{~g}$ of nerve after sampling) loaded onto a sucrose- $\mathrm{NaCl}$ density gradient in a Beckman Ti-60 zonal rotor. The gradient was formed as previously described by Whittaker et al. (1972), as modified by Ohsawa et al. (1979) except that the light solution consisted of $0.2 \mathrm{M}$ sucrose and $0.311 \mathrm{M} \mathrm{NaCl}$, the switch from the first dense solution ( $1.2 \mathrm{M}$ sucrose) to the second (1.6 M sucrose) took place after only $100 \mathrm{ml}$ of gradient had been delivered, and the overlay was $30 \mathrm{ml}$. Moreover, all solutions contained the additions noted above. After $3 \mathrm{~h}$ at $50,000 \mathrm{rpm}$, the gradient was pumped out, collected in 5-ml fractions, and the fractions analysed for marker substances (see below).

In some experiments, unstimulated electric tissue was extracted and the extracts separated in a zonal rotor exactly as described by Agoston et al. (1986) except that eserine was omitted. Vesicles were counted in fractions by a modification (to be published) of the method of Ohsawa et al. (1979).

Subcellular fractionation of electric lobe. Freshly dissected electric lobes $(0.8-1.2 \mathrm{~g}$ from two to four fish) were homogenized in ice-cold $0.367 \mathrm{M}$ sucrose- $0.224 \mathrm{M} \mathrm{NaCl}$ with the usual additions, except that the pH of the HEPES buffer was 7.0. The tissue was first homogenized by hand with five passes of the pestle in a 30-ml loosely fitting Dounce-type glass homogenizer (Braun L-type, Melsungen, F.R.G.); after a 5-min period of cooling in ice, the homogenate was transferred to a motor-driven $10-\mathrm{ml}$ Teflon-glass homogenizer and 16 passes of the Teflon pestle were made during $1 \mathrm{~min}$ at 800 rpm followed by a 5 -min cooling period in ice. This homogenization was repeated once more. The homogenate was then centrifuged at $1,000 \mathrm{~g}_{\mathrm{av}}$ for $10 \mathrm{~min}$ and the resulting pellet $\left(\mathrm{P}_{1}\right)$ washed by homogenizing it in fresh medium and centrifuging as before. The combined supernatants $\left(S_{1}\right)$ were then centrifuged at $10,000 \mathrm{gav}_{\mathrm{av}}$ for $30 \mathrm{~min}$ to give a pellet $\left(\mathrm{P}_{2}\right)$ and a supernatant $\left(S_{2}\right) . P_{1}$ and $S_{1}$ fractions were also prepared from the rest of the Torpedo brain.

Other subcellular fractions. For purposes of comparison, chromaffin granules were prepared from ox adrenal medullae as described by Smith and Winkler (1967) and electromotor synaptic vesicles were prepared from unstimulated tissue by our current standard procedure (Agoston et al., 1986).

Further fractionation by particle exclusion chromatography The $S_{2}$ fraction from electric lobe was fractionated further by applying it $(1 \mathrm{ml})$ to a conditioned $60 \times 1 \mathrm{~cm}$ column of Sephacryl-1000 (Pharmacia, Freiburg, F.R.G.). The elution buffer, degassed before use, consisted of $0.21 \mathrm{M}$ sucrose, 0.31 $M \mathrm{NaCl}$, and the additions mentioned earlier, and was collected in 2-ml fractions. Before use, the column was equilibrated with the elution buffer by washing it with several bed volumes of buffer at a flow rate of $20 \mathrm{ml} \mathrm{h}^{-1}$, conditioned by passing samples of an $S_{1}$ fraction from Torpedo brain (less electric lobes) through it and calibrated with chromaffin granules and electromotor synaptic vesicles.

\section{Assay of neuroactive substances}

Acetylcholine. This was assayed on small slips of the dorsal muscle of the leech (Whittaker and Barker, 1972). Acetylcholine was released from particles and stabilized by acidifying samples of subcellular fractions to $\mathrm{pH} 4.0$ and storing them at $-20^{\circ} \mathrm{C}$ until assayed.

VIPLI. This was extracted from fractions either (a) by adding 10 volumes of boiling distilled water to the samples, maintaining them at $95^{\circ} \mathrm{C}$ for $5 \mathrm{~min}$ in a boiling water bath, then cooling them in ice and adding acetic acid to a final concentration of $0.5 \mathrm{M}$; or (b) using 10 volumes of hot $\left(95^{\circ} \mathrm{C}\right.$ ) $0.05 \mathrm{M} \mathrm{HCl}$ in place of the boiling water; or (c) using acidified ethanol as previously described by Fahrenkrug (1985). The various methods gave similar results. Ethanol was evaporated from samples in a vacuum centrifuge and all samples were 
lyophilized in a freeze-drier equipped with a vacuum centrifuge. VIPLI was assayed using synthetic porcine VIP as standard and the results expressed as femtomoles of porcine VIP equivalents (fmol-eq) (Agoston and Conlon, 1986).

$A T P$. This was determined in deproteinized supernatants of samples of subcellular fractions by the luciferin-luciferase bioluminescence method (Stanley and Williams, 1969). The distribution of ATP in the gradients, its specific concentration, enrichment factors, and recovery closely followed those of acetylcholine and its assay was done mainly as a rapid means of locating the fractions containing synaptic vesicles before assaying for acetylcholine and the stable vesicle markers.

\section{Enzyme assays}

Phosphatases. $\mathrm{Mg}^{2+}$-dependent ATPase (EC 3.6.1.3) was determined in the presence of oligomycin and ouabain as described by Harlos et al. (1984). Thiamine pyrophosphatase (EC 3.6.1.1) (TPPase) was measured by an adaptation of the histochemical method of Johansson (1983); thiamine pyrophosphate (Sigma, Deisenhofen, F.R.G.) $(1.0 \mathrm{~m} M)$ was the substrate and the assay mixture also contained $6.0 \mathrm{mM} \mathrm{MgCl} 2$ in a Tris-maleate or Tris- $\mathrm{HCl}$ buffer, $\mathrm{pH} 7.2$. The reaction was stopped after $60-90 \mathrm{~min}$ at room temperature $\left(20^{\circ} \mathrm{C}\right)$ by the addition of ice-cold perchloric acid (Suprapure, Merck, Darmstadt, F.R.G.) to a final concentration of $5 \%$ and by placing the samples on ice. Inorganic phosphate $\left(\mathbf{P}_{\mathbf{i}}\right)$ was usually determined in protein-free supernatants according to Lanzetta et al. (1979); however, in some determinations, Triton X-100 (Sigma) replaced Flaminox (Fischer, Meckenheim, F.R.G.) and had identical stability and sensitivity. Because Torpedo tissues have a high endogenous $\mathrm{P}_{\mathrm{i}}$ content, care was taken to deduct this from the total $P_{i}$ of each sample.

Other enzymes. Choline acetyltransferase (EC 2.3.1.6) (ChAT) was measured according to Fonnum (1975) and lactate dehydrogenase (EC 1.1.1.27) (LDH) as described by Johnson (1960). Free enzyme activity was determined under isoosmotic conditions and total activity under hypoosmotic conditions in the presence of detergent (Whittaker and Barker, 1972).

\section{Immunochemical assays}

Sample preparation and dot assay. Particulate material was sedimented from zonal or chromatographic fractions in a Beckman Airfuge and antigens extracted from it essentially by Method 2 of Agoston et al. (1986) with some minor modifications suggested by Hell (1987). Samples were dotted onto nitrocellulose paper (Bio-Rad, Munich, F.R.G.) for immediate assay or stored at $-80^{\circ} \mathrm{C}$ until required. To facilitate comparisons between different assays, a fixed amount of a standard extract of purified Torpedo synaptic vesicles was also dotted and the radioactivity expressed as a percentage of that of the vesicle standard. The resulting scores are referred to as "synaptic vesicle equivalents" (SV-eq).

Antibodies. For the assay of vesicular proteoglycan (Agoston et al., 1986) two antivesicular proteoglycan antisera of Walker et al. (1983) were used. For the assay of synaptophysin, an anti-synaptophysin polyclonal antibody kindly provided by Dr. E. Floor was used; this is designated R10 and was characterized by Buckley et al. (1987). In some experiments two monoclonal antibodies, designated SY38 (Wiedenmann and Franke, 1985) and C 7.2 (Jahn et al., 1985), were also used; SY38 (now commercially available through Boehringer, Mannheim, F.R.G.) was a kind gift from Dr. B. Wiedenmann and a small amount of $C 7.2$ was made available through Herrn J. W. Hell with the kind approval of Dr. R. Jahn.

\section{Electron microscopy}

Fractions derived from zonal density gradient separations were pooled according to their content of acetylcholine, ATP, or VIPLI and fixed, pelleted, washed, and processed as previously described by Agoston et al. (1985a). Sections cut from material embedded in Epon 812 were viewed after lead citrate staining in a Jeol 100B electron microscope. Particle diameters were measured in a Zeiss particle-size analyzer on electron micrographs at a magnification of 15,000 and the results were evaluated as previously described by Agoston et al. $(1985 b)$.

Ligation of electromotor nerves was carried out as described by Agoston and Conlon (1986); after 3 days, the proximal segments were excised and prepared for electron microscopy as described above.

\section{Analysis of proteins}

Protein content of extracts and fractions. This was determined by the method of Peterson (1977).

Separation. This was performed by sodium dodecyl sulphate-polyacrylamide gel electrophoresis (SDS-PAGE) according to Laemmli (1970) using the buffers and gel compositions described by Agoston et al. (1985b).

\section{RESULTS}

\section{Electric organ}

Separation of VIPLI storage particles from synaptic vesicles by density gradient separation in a zonal rotor. Figure 1 shows the distribution of neuroactive substances, putative stable vesicle markers, and markers for Golgi membranes and the cytosol in a zonal density gradient after separation of a cytoplasmic extract of frozen and crushed electric organ. The experiment shown was one of five, all of which gave similar results. Table 1 gives the densities, specific activities, enrichment factors, and recoveries for the constituents of the various peaks.

It will be seen, in Fig. 1a, that acetylcholine and VIPLI form distinct, well-separated peaks, the particles containing VIPLI being considerably denser than the acetylcholine-rich synaptic vesicles. The sucrose of the gradient used in these runs rose in an approximately linear fashion between gradient fractions $15(75 \mathrm{ml})$ and $40(200 \mathrm{ml})$ at an average rate of about $6.4 \mu \mathrm{mol}$ $\mathrm{ml}^{-1}$; this profile was indeed selected after preliminary trials to give an optimum separation between the two peaks, albeit at the expense of a poorer separation of the acetylcholine peak from soluble protein (Fig. Ib) than that given by our standard procedure (Agoston et al., 1986 and references therein). This, and the rapid rise in sucrose concentration at the beginning of the gradient to relatively high values, may account for the rather low acetylcholine content of the vesicle peak per milligram of protein and its rather high density. The latter contrasts with the value of $1.055 \mathrm{~g} \mathrm{ml}^{-1}$ obtained in isoosmotic glycine-sucrose gradients (Giompres et al., 1981) and may be due to the penetration of sucrose into the vesicle core and/or osmotic dehydration induced by exposure to the hyperosmotic sucrose-containing gradient used here. 

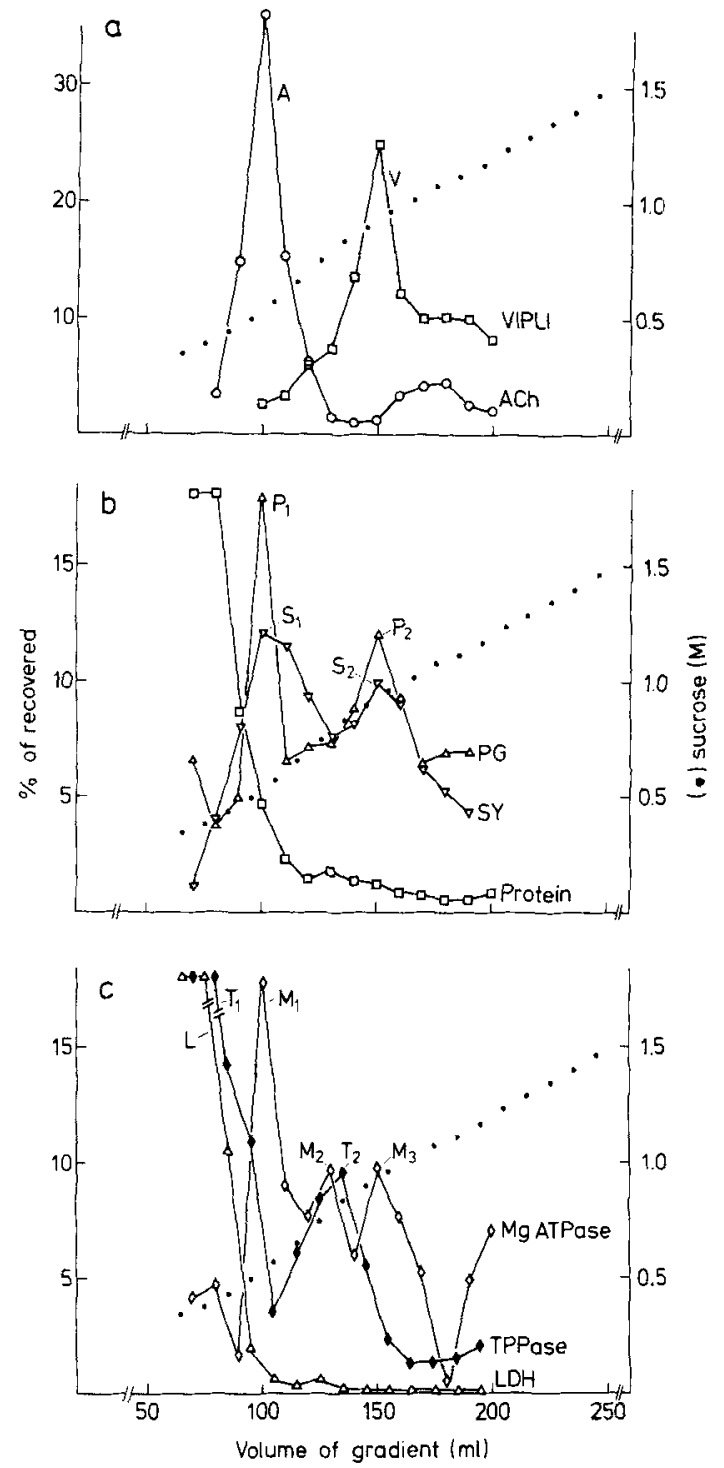

FIG. 1. Distribution, in a zonal density gradient, of neuroactive and marker substances present in a cytoplasmic extract (fraction $S_{12}$ ) from electric organ. Acetylcholine (open circles, $A C h$ ), and VIPLI (open squares). b: Vesicular proteoglycan (open triarigles, $P G$ ), synaptophysin (inverted open triangles, SY), and protein (open squares). c: $\mathrm{Mg}^{2+}$-dependent ATPase (open diamonds, MgATF'ase), TPPase (filled diamonds), and lactate dehydrogenase (open triangles, LDH). The small filled circles show the sucrose concentration. Peaks have been labelled to correspond with Table 1. Distributions have been normalized. Densities, specific concentrations, and enrichment factors relative to the parent fraction for each peak and the total recovery in the gradient of each component are given in Table 1.

This result clearly shows that acetylcholine and VIPLI are packaged differently in the electromotor synapse than in the guinea-pig myenteric plexus (Agoston et al., 1985b, 1988b); moreover there is no evidence for the presence of acetylcholine in the VIPLI-containing particles as there is in the myenteric plexus. The low shoulder of VIPLI in dense fractions which also contain a small amount of acetylcholine is probably due to the presence of small numbers of synap- tosomes in this part of the gradient (see Zimmermann and Denston, 1977).

A second interesting finding is that the three stable putative synaptic vesicle markers, vesicular proteoglycan, synaptophysin, and the $\mathrm{Mg}^{2+}$-dependent ATPase are all distributed in the gradient (Fig. 1 and Table 1) such that they show an initial peak $\left(P_{1}, S_{1}\right.$, and $\left.M_{1}\right)$ coinciding with the acetylcholine-rich synaptic vesicle peak and another one $\left(\mathrm{P}_{2}, \mathrm{~S}_{2}\right.$, and $\left.\mathrm{M}_{3}\right)$ with the VIPLI peak. This shows that these important structural and functional components are not synaptic-vesicle specific but are present in the other main type of storage particle in the terminal. Whereas vesicular proteoglycan and synaptophysin are bimodal in distribution, $\mathrm{Mg}^{2+}$-dependent ATPase is actually trimodal, with an intermediate peak $\left(\mathrm{M}_{2}\right)$ corresponding to that of TPPase $\left(\mathrm{T}_{2}\right)$. The significance of this particulate TPPase peak is not clear; it may represent a terminal extension of the neuronal Golgi membrane system, but may equally well be derived from elements of the electrocytes. Also unexplained is the large peak $\left(T_{1}\right)$ of soluble TPPase at the beginning of the gradient. The soluble cytoplasmic marker LDH was recovered, as expected, almost entirely in the initial peak (L) of cytoplasmic protein.

Morphology of storage particles. The material in the acetylcholine peak (Fig. 1, fractions 18-22; 85-110 ml) and in the TPPase and VIPLI peaks (Fig. 1, fractions $24-36 ; 115-180 \mathrm{ml}$ ) were separately pooled and prepared for electron microscopy. Representative fields are shown in Fig. $2 b$ and $a$, respectively. The VIPLI peak (Fig. 2a) is seen to contain numerous dense-cored vesicles (arrows) and other vesicles of similar size with electron-lucent cores, together with larger vesiculated membrane fragments (open arrow). By analogy with findings from other tissues, especially myenteric plexus (Agoston et al., 1985b), the dense-cored vesicles are tentatively identified as the VIPLI-containing particles; the similarly sized empty vesicles may be dense-cored vesicles that have lost their cores. The larger membrane fragments may include fragments of TPPase-rich Golgi membranes because the TPPase $\left(T_{2}\right)$ and intermediate $\left(\mathrm{M}_{2}\right) \mathrm{Mg}^{2+}$-ATPase peaks overlapped with the VIPLI peak. The morphology is in marked contrast to that of the acetylcholine-rich synaptic vesicle fraction (Fig. 2b).

In intact electromotor nerve terminals (Fig. $2 c$ and d), dense-cored vesicles similar to those seen in Fig. 2a are not common, but they do occur (arrows).

The profile diameter distributions of the particles in the two peaks are shown in the inset in Fig. 3. The median diameters are $70 \mathrm{~nm}$ and $115 \mathrm{~nm}$ for synaptic vesicles and VIPLI-associated vesicles, respectively. Application of the Abercrombie (1946) correction gives 89 and $146 \mathrm{~nm}$, respectively, for the spherical diameters. Electromotor synaptic vesicles have previously been shown to have a diameter of about $90 \mathrm{~nm}$ (Giompres et al., 1981).

Particle counts. In zonal runs performed for other purposes (V. P. Whittaker, G. H. C. Dowe, G. Q. Fox, 
TABLE 1. Densities, concentrations, and enrichment factors of zonal density gradient peaks of neuroactive substances, marker enzymes, and putative vesicle-specific antigens, and the recoveries of these components, derived from cytoplasmic extracts of Torpedo electric organ

\begin{tabular}{|c|c|c|c|c|c|c|}
\hline Component & Peak & Unit & $\begin{array}{l}\text { Density } \\
\left(\mathrm{g} \mathrm{ml}^{-1}\right)\end{array}$ & $\begin{array}{l}\text { Specific concentration } \\
\text { [units (mg of protein })^{-1} \text { ] }\end{array}$ & $\begin{array}{l}\text { Enrichment factor } \\
\text { (relative to } S_{12} \text { ) }\end{array}$ & $\begin{array}{l}\text { Recovery } \\
\text { (percentage of parent fraction) }\end{array}$ \\
\hline $\mathrm{ACh}$ & A & $\mathrm{nmol}$ & 1.0696 & $328 \pm 48$ & $63 \pm 7$ & $72 \pm 8$ \\
\hline VIPLI & V & fmol-eq & 1.1218 & $1,411 \pm 214$ & $22 \pm 4$ & $46 \pm 6$ \\
\hline$P G$ & $\begin{array}{l}P_{1} \\
P_{2}\end{array}$ & SV-eq & $\begin{array}{l}1.0696 \\
1.1218\end{array}$ & $\begin{array}{c}100^{c} \\
49 \pm 8\end{array}$ & $\left.\begin{array}{l}38 \pm 5 \\
18 \pm 3\end{array}\right\}$ & $77 \pm 8$ \\
\hline SY & $\begin{array}{l}\mathrm{S}_{1} \\
\mathrm{~S}_{2}\end{array}$ & SV-eq & $\begin{array}{l}1.0696 \\
1.1218\end{array}$ & $\begin{array}{c}100^{c} \\
58 \pm 9\end{array}$ & $\left.\begin{array}{l}41 \pm 5 \\
23 \pm 4\end{array}\right\}$ & $74 \pm 9$ \\
\hline MgATPase & $\begin{array}{l}\mathrm{M}_{1} \\
\mathrm{M}_{2} \\
\mathrm{M}_{3}\end{array}$ & $n m o l P_{i} h^{-1}$ & $\begin{array}{l}1.0696 \\
1.1081 \\
1.1218\end{array}$ & $\begin{array}{l}688 \pm 79 \\
425 \pm 61 \\
508 \pm 65\end{array}$ & $\left.\begin{array}{l}22 \pm 4 \\
14 \pm 3 \\
16 \pm 3\end{array}\right\}$ & $97 \pm 8$ \\
\hline TPPase & $\begin{array}{l}\mathrm{T}_{1} \\
\mathrm{~T}_{2}\end{array}$ & $n m o l P_{i} h^{-1}$ & $\begin{array}{l}1.0501 \\
1.1081\end{array}$ & $\begin{array}{l}285 \pm 34 \\
652 \pm 87\end{array}$ & $\left.\begin{array}{r}7 \pm 2 \\
16 \pm 3\end{array}\right\}$ & $95 \pm 8$ \\
\hline
\end{tabular}

ACh, acetylcholine; PG, proteoglycan; SY, synaptophysin; MgATPase, $\mathrm{Mg}^{2+}$-dependent ATPase; others as in text.

${ }^{a}$ Mean of five experiments; the minimum significant difference in density is the difference in mean density between adjacent 5 -ml fractions, i.e., $0.004 \mathrm{~g} \mathrm{ml}^{-1}$ or about $0.4 \%$ of the means. The SEM values were less than this.

${ }^{b}$ Means \pm SEM of five experiments.

${ }^{c}$ By definition (see text).

and D. Kötting, in preparation) using the somewhat different gradient profile of our current standard procedure (Agoston et al., 1986), the number of vesicles in the various fractions was counted by a modification of the method of Ohsawa et al. (1979) with a cutoff of $160 \mathrm{~nm}$. It was noted that in addition to the main vesicle peak at a density of $1.069 \mathrm{~g} \mathrm{ml}^{-1}$ (peak I) there were two smaller peaks (II and III) of densities 1.1075 and $1.1260 \mathrm{~g} \mathrm{ml}^{-1}$ (ranges 1.100-1.160 and 1.160$1.460 \mathrm{~g} \mathrm{ml}^{-1}$, respectively) corresponding fairly well to those of the $\mathrm{M}_{2}$ peak of $\mathrm{Mg}^{2+}$-dependent ATPase (arrow) and the VIPLI-containing particles (Fig. 3).

An attempt was made to correlate the proportion of the stable vesicle markers recovered in the light, synaptic vesicle peak with that of the vesicular membranes. This involved several assumptions. First, the separation of peaks was not complete and assignments were somewhat arbitrary: intermediate fractions were divided equally between the peaks that they separated. Second, a correction derived from the mean vesicle diameters of the light and heavy fractions was applied to allow for the fact that each larger vesicle in the denser region of the gradient contributed almost twice the area of membrane that each smaller synaptic vesicle contributed. It was found (Table 2) that fewer of the stable markers were recovered in the synaptic vesicle fraction than would have been expected on the basis of the proportion of the total vesicle membrane recovered there, if all vesicle membranes had the same composition. The best correlation was found with synaptophysin; with the other two markers, the distribution was such as to suggest either that the membranes of the dense vesicles are over twice as rich in proteoglycan and $\mathrm{Mg}^{2+}$-dependent ATPase than those of synaptic vesicles or that membranes over the cutoff point of 160 $\mathrm{nm}$ also contained these markers. Such membranes would, on account of their larger surface area, contribute disproportionately to the total membrane present.
Further evidence for the presence of membrane components common to the acetylcholine- and VIPLIrich vesicles was obtained by SDS-PAGE (results not shown). Nine bands, among them components previously identified by Tashiro and Stadler (1978) in highly purified synaptic vesicles, were common to both peaks.

\section{Electromotor nerves}

Density gradient separation. The corresponding results for electromotor nerves are shown in Figs. 2 and 4 , and Table 3. Again, vesicle proteoglycan and synaptophysin are both distributed bimodally in the gradient (Fig. 4b); their denser peak is associated with a peak of VIPLI and their less dense, with acetylcholine (Fig. 4a).

The particles of the VIPLI peak closely resemble their counterparts from electric organ (compare Table 3 , lines 3,6 , and 8 with Table 1 , lines 2,4 , and 6 ). Thus, they differ in density by $<2 \%$ and their ratios of VIPLI, proteoglycan, and $\mathrm{Mg}^{2+}$-dependent ATPase to synaptophysin taken as 100 are extremely close (Table 4).

In contrast to VIPLI, the distribution of acetylcholine differed significantly from that seen in gradients derived from electric organ. It reproducibly formed two partially resolved peaks. The denser of these was clearly associated with the three stable vesicle markers (compare Table 3, line 1 with lines 5 and 7), but the acetylcholine content per unit of synaptophysin or vesicular proteoglycan was less than one-thousandth that of the synaptic vesicles from electric organ (note difference in units between Table 1, line 1 and Table 3, line 1). The less dense of the two peaks of acetylcholine was just within the initial peak of soluble cytoplasmic protein and had little of the stable synaptic vesicle markers associated with it; we believe it to be soluble acetylcholine. It has been estimated that up to $80 \%$ of the acetylcholine content of cholinergic nerves may be 

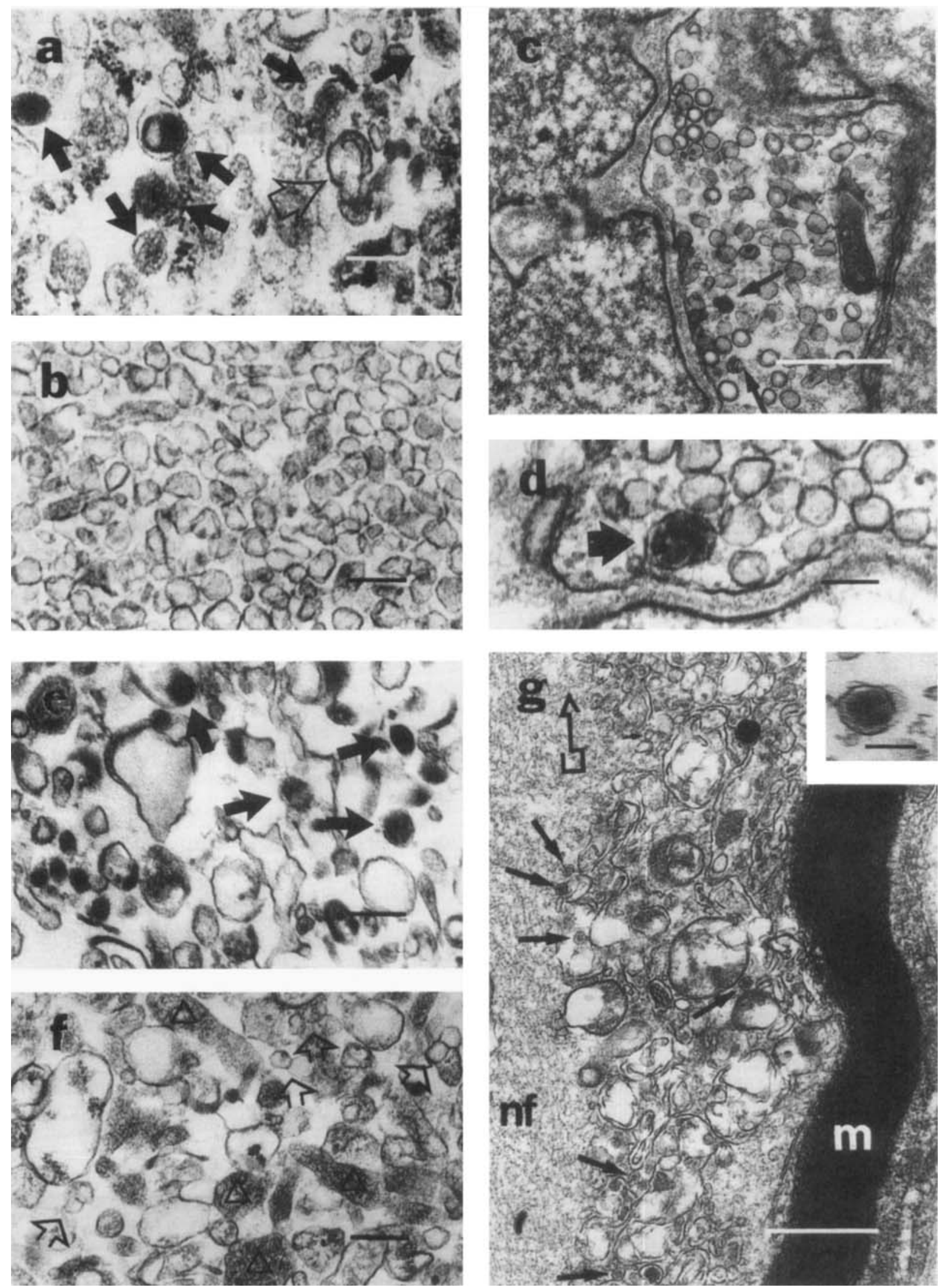


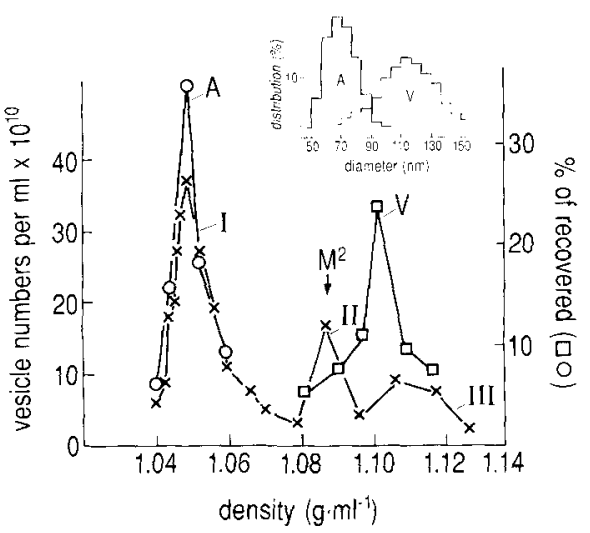

FIG. 3. Distribution $(X)$ of vesicle numbers in a zonal density gradient loaded with a sample of $S_{12}$ derived from $64 \mathrm{~g}$ of electric organ tissue. To facilitate comparison with Fig. 1 and Table 1, the number of vesicles has been plotted against density and the distributions of acetylcholine (circles, ACh, peak A) and VIPLI (squares, peak $V$ ) from Fig. 1 have been superimposed. The arrow indicates the position of peak $M_{2}$. It will be seen that the less dense peak I of vesicle numbers coincides with acetylcholine, the denser peak III with VIPLI, and the intermediate peak (II) with $\mathrm{M}_{2}$. The relative number of particles in the light (I) and dense (II and III) peaks is given in Table 2. Inset: Distribution of particle diameters in two fractions containing acetylcholine (thick line) or VIPLI (thin line).

cytoplasmic. Although a specific cholinesterase inhibitor was not added, the protease inhibitor PMSF was found to inhibit the low ( $2 \%$ of electric organ) axonal cholinesterase sufficiently to allow for the survival of part of this cytoplasmic acetylcholine. In the case of electric organ, with its much higher cholinesterase content, enough cholinesterase must have survived to destroy the soluble acetylcholine that is detected in early fractions of the gradient when $0.1 \mathrm{~m} M$ eserine is present (Agoston et al., 1986).

TABLE 2. Distribution of vesicle membrane and stable vesicle markers in light and dense vesicle peaks containing acetylcholine and VIPLI, respectively

\begin{tabular}{lc}
\hline Parameter & $\begin{array}{c}\text { Percentage of total recovered } \\
\text { in synaptic vesicles }\end{array}$ \\
\hline Vesicle membrane & $67^{\circ}$ \\
Synaptophysin & 58 \\
Proteoglycan & 42 \\
$\mathrm{Mg}^{2+}$-ATPase & 43 \\
\hline
\end{tabular}

${ }^{a}$ A factor of 0.36 (i.e., $90^{2} / 150^{2}$ ) was applied to the number of synaptic vesicles to allow for differences in the mean diameters of the two populations.
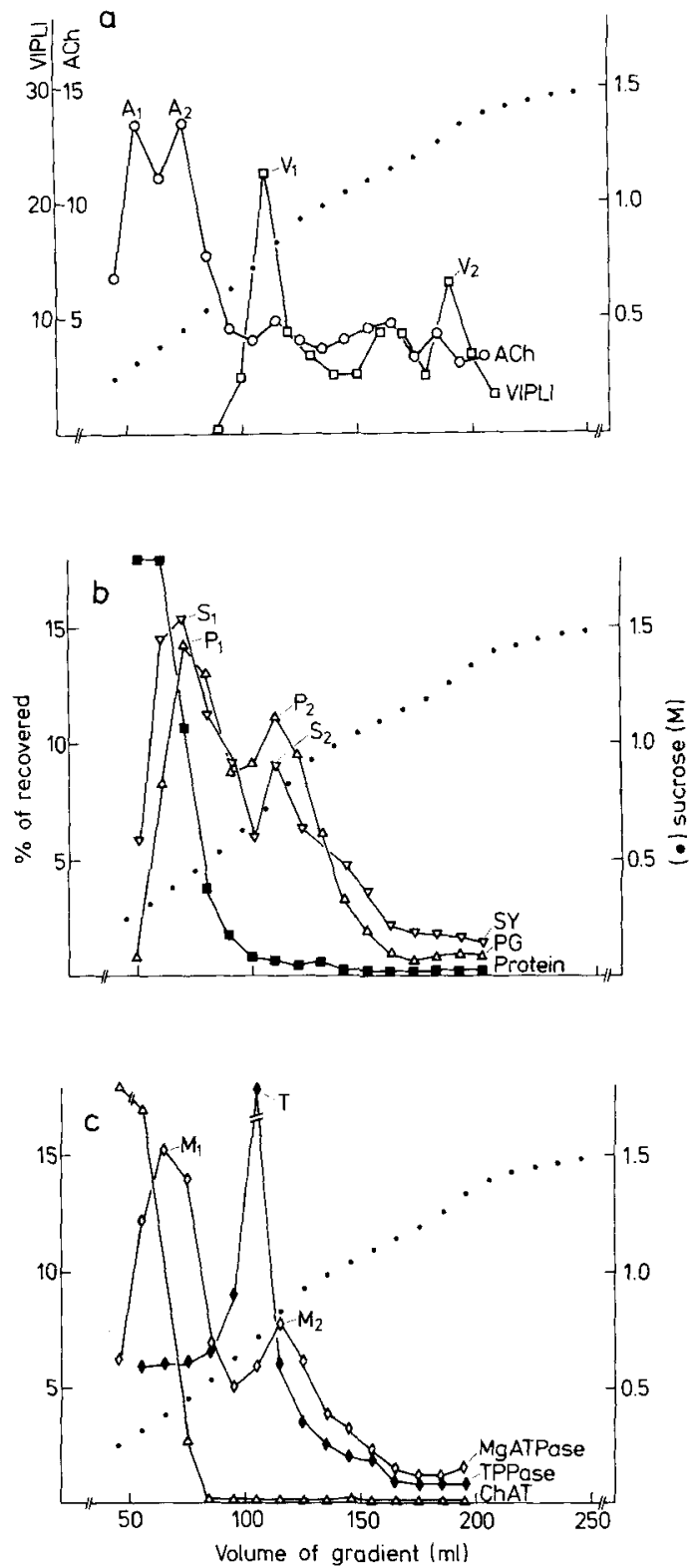

FIG. 4. Distribution, in a zonal density gradient, of neuroactive and marker substances present in a cytoplasmic extract (fraction $S_{12}$ ) from electromotor nerves. a: Acetylcholine (open circles, $A C h$ ) and VIPLI (open squares). b: Vesicular proteoglycan (open triangles, $P G$ ), synaptophysin (inverted open triangles, SY), and protein (filled squares). $\mathrm{c}: \mathrm{Mg}^{2+}$-dependent ATPase (open diamonds, MgATPase), TPPase (filled diamonds), and ChAT (open triangles). The small filled circles show the sucrose concentration. Peaks have been labelled to correspond to Table 3 and distributions have been normalized. Densities, specific concentrations, and enrichment factors relative to the parent fraction for each peak and the total recovery in the gradient of each component are given in Table 3.

FIG. 2. Electron micrographs of particulate material present in $(\mathbf{a}, \mathbf{e})$ the VIPLI peak, $(b, f)$ the acetylcholine peak derived from $(a, b)$ electric organ, $(e, f)$ electromotor nerves. $c$, d: Electromotor nerve terminals in situ showing dense-cored vesicles (arrows) and numerous synaptic vesicles; note the resemblance to isolated dense-cored vesicles (arrows) and synaptic vesicles in a and b, respectively. g: Axoplasm of electromotor nerve just proximal to a ligature showing numerous vesicles resembling those in $\mathrm{e}$ and $\mathrm{f}$. In $\mathrm{g}$, $\mathrm{m}$ indicates a portion of the myelin sheath, $\mathrm{nf}$, neurofilaments, and the crooked arrow points toward the ligature. The inset shows a dense-cored vesicle at the same magnification as a, b, and d. Bars represent: $\mathrm{a}, \mathrm{b}, \mathrm{d}$ and inset in $\mathrm{g}, 0.1 ; \mathrm{e}, \mathrm{f}, 0.2 ; \mathrm{c}, 0.5 ; \mathrm{g}, 1 \mu \mathrm{m}$. 
TABLE 3. Densities, concentrations, and enrichment factors of zonal density-gradient peaks of neuroactive substances, marker enzymes and vesicle-specific antigens, and the recoveries of these components, derived from cytoplasmic extracts of Torpedo electromotor nerves

\begin{tabular}{|c|c|c|c|c|c|c|}
\hline Component & Peak & Unit & $\begin{array}{l}\text { Density } \\
\left(\mathrm{g} \mathrm{ml}^{-1}\right)\end{array}$ & $\begin{array}{l}\text { Specific concentration } \\
\\
\text { [units (mg of protein) }^{-1} \text { ] }\end{array}$ & $\begin{array}{l}\text { Enrichment factor } \\
\text { (relative to } S_{12} \text { ) }\end{array}$ & $\begin{array}{c}\text { Recovery } \\
\text { (percentage of parent fraction) }\end{array}$ \\
\hline \multirow[t]{2}{*}{$\mathrm{ACh}$} & $A_{1}$ & pmol & 1.0400 & $45 \pm 6$ & $1.8 \pm 1\}$ & \multirow[b]{2}{*}{$67 \pm 5$} \\
\hline & $A_{2}$ & & 1.0570 & $211 \pm 19$ & $8.4 \pm 3$ & \\
\hline \multirow[t]{2}{*}{ VIPLI } & $V_{1}$ & fmol-eq & 1.1001 & $1,328 \pm 159$ & $17 \pm 4$ & \multirow{2}{*}{$51 \pm 7$} \\
\hline & $V_{2}$ & & 1.1683 & $681 \pm 88$ & $9 \pm 3\}$ & \\
\hline \multirow[t]{2}{*}{ PG } & $P_{i}$ & SV-eq & 1.0527 & $85 \pm 9$ & $19 \pm 3\}$ & \multirow{2}{*}{$71 \pm 9$} \\
\hline & $\mathrm{P}_{2}$ & & 1.1001 & $41 \pm 6$ & $9 \pm 3\}$ & \\
\hline \multirow[t]{2}{*}{ SY } & $S_{1}$ & SV-eq & 1.0527 & $91 \pm 10$ & $21 \pm 4\}$ & \multirow{2}{*}{$79 \pm 9$} \\
\hline & $\mathrm{S}_{2}$ & & 1.1001 & $55 \pm 8$ & $12 \pm 3\}$ & \\
\hline \multirow[t]{2}{*}{ MgATPase } & $\mathrm{M}_{1}$ & $n m o l P_{i} h^{-1}$ & 1.0480 & $215 \pm 29$ & $6 \pm 2$ & \multirow{2}{*}{$86 \pm 7$} \\
\hline & $\mathrm{M}_{2}$ & & 1.1063 & $403 \pm 51$ & $11 \pm 3\}$ & \\
\hline TPPase & $\mathrm{T}$ & $n m o l P_{i} h^{-1}$ & 1.0938 & $100 \pm 14$ & $27 \pm 4$ & $89 \pm 9$ \\
\hline
\end{tabular}

Abbreviations as in Table 1.

${ }^{a}$ Means of three experiments; the minimum significant difference in density is the difference in mean density between adjacent 5 -ml fractions, i.e., $0.004 \mathrm{~g} \mathrm{ml}^{-1}$ or about $0.4 \%$ of the means. The SEM values were less than this.

${ }^{b}$ Means \pm SEM values of three experiments.

The small peak of VIPLI in the densest region of the gradient which is also associated with small amounts of acetylcholine, though not with significant amounts of the stable vesicle markers, may represent neuroactive material entrapped within vesiculated membrane fragments derived from these membranerich, heavily myelinated nerves on comminution. Electron micrographs (not shown) confirmed that such fragments are numerous in this part of the gradient.

Morphology. The particles of the two synaptophysinand proteoglycan-rich peaks containing acetylcholine (Fig. 2f) and VIPLI (Fig. 2e) resembled their electric organ counterparts (Fig. 2b and a) except that the synaptic vesicle peak was less morphologically homogeneous than that derived from electric organ; the main contaminants were probably fragments of the myelin and Schwann-cell sheaths. It is clear that our isolation technique does not yield such pure fractions of synaptic vesicles from nerve axons as from electric organ.

In normal axons, vesicles of any kind are rare; however, their presence may readily be demonstrated by ligating the axon, which causes them to accumulate above the constriction (Whittaker et al., 1975). An electron micrograph of a region proximal to a 3-day old ligature is shown in Fig. $2 \mathrm{~g}$; it will be seen that numerous vesicles have accumulated, among them those of diameters and morphologies similar to those of the isolated vesicles in the synaptophysin- and proteoglycan-containing VIPLI and acetylcholine peaks (Fig. $2 \mathrm{e}$ and $\mathrm{f}$ ). The arrows point to examples of membrane-bound dense-cored vesicles similar to those seen in Fig. 2a, c, d, and e and their fine structure is demonstrated more clearly in the enlargement inserted into the figure.

The distribution of TPPase and $\mathrm{Mg}^{2+}$-dependent ATPase in the gradient differs somewhat from that seen in electric organ-derived gradients. Membrane-bound TPPase sediments to about the same region of the gradient but its specific activity is less than one-sixth that of the corresponding fraction from electric organ and there is no soluble fraction. $\mathrm{Mg}^{2+}$-dependent ATPase forms peaks in association with both the acetylcholineand VIPLI-containing particles, along with the other stable markers synaptophysin and vesicle proteoglycan; it shows no clearly defined peak corresponding to that of TPPase but there is more than sufficient activity in

TABLE 4. Comparison of axonal and terminal synaptic and dense vesicles

\begin{tabular}{|c|c|c|c|c|c|}
\hline \multirow[b]{2}{*}{ Site } & \multirow[b]{2}{*}{$\begin{array}{l}\text { Density } \\
\left(\mathrm{g} \mathrm{ml}^{-1}\right)\end{array}$} & \multicolumn{4}{|c|}{ Content (units per 100 units of synaptophysin) } \\
\hline & & $\begin{array}{l}\text { Acetylcholine } \\
\text { (nmol) }\end{array}$ & $\begin{array}{c}\text { VIPLI } \\
\text { (fmol-eq) }\end{array}$ & $\begin{array}{l}\text { Proteoglycan } \\
\text { (SV-eq) }\end{array}$ & $\begin{array}{l}\mathrm{Mg}^{2+} \text {-ATPase } \\
\left(\mathrm{nmol} \mathrm{P}_{\mathrm{i}} \mathrm{h}^{-1}\right)\end{array}$ \\
\hline \multicolumn{6}{|c|}{ Synaptic vesicles } \\
\hline Terminals & 1.070 & 328 & - & 100 & 688 \\
\hline Axons & 1.057 & 0.23 & - & 93 & 236 \\
\hline \multicolumn{6}{|l|}{ Dense vesicles } \\
\hline Terminals & 1.122 & -- & 2,432 & 84 & 876 \\
\hline Axons & 1.100 & - & 2,414 & 75 & 733 \\
\hline
\end{tabular}


this region of the gradient to satisfy the requirements of membrane fragments with the same $\mathrm{Mg}^{2+}$-ATPaseto-TPPase activity ratio as those derived from electric organ. The soluble cytoplasmic enzyme ChAT (Fig. 4c) was recovered, as expected, in the initial peak of soluble cytoplasmic protein.

The polypeptide compositions, as revealed by SDSPAGE (not shown), of the fractions containing acetylcholine and VIPLI storage particles derived from the electromotor nerves were compared with those of the corresponding fractions from electric organ. There was a general similarity between the electropherograms of the particles from the two sources, that between those of the VIPLI-containing particles being particularly close.

\section{Electric lobe}

Fractionation of tissue. The small amount of tissue available, its consistency, and its relatively low acetylcholine and VIPLI content rendered it unsuitable for fractionation studies exactly parallelling those carried out with electric organ and electromotor nerves. Accordingly, the tissue was homogenized by liquid shear of increasing intensity, the homogenate fractionated by moving-boundary ("differential") centrifugation, and the VIPLI- and acetylcholine-rich supernatant fractionated by exclusion chromatography. The results are presented in Table 5 and Fig. 5. Compared to mammalian cortex, electric lobes are not rich in synaptic contacts, and such synapses as occur are all of one type-axodendritic-formed by axons of the neurones of the oval nucleus synapsing with dendrites of the electromotor neurones. Thus, although synaptosomes are formed on homogenizing the electric lobes (V. P. Whittaker, unpublished observations), acetylcholine and other cholinergic markers are localized, not in them, but in the electromotor cell bodies. Acetylcholine surviving homogenization in the absence of an anticholinesterase would be expected to be vesicle bound and to be mainly recovered in the $S_{2}$ fraction. Table 5 , line 2 shows that this indeed is what was found. VIPLI, also known on immunocytochemical evidence

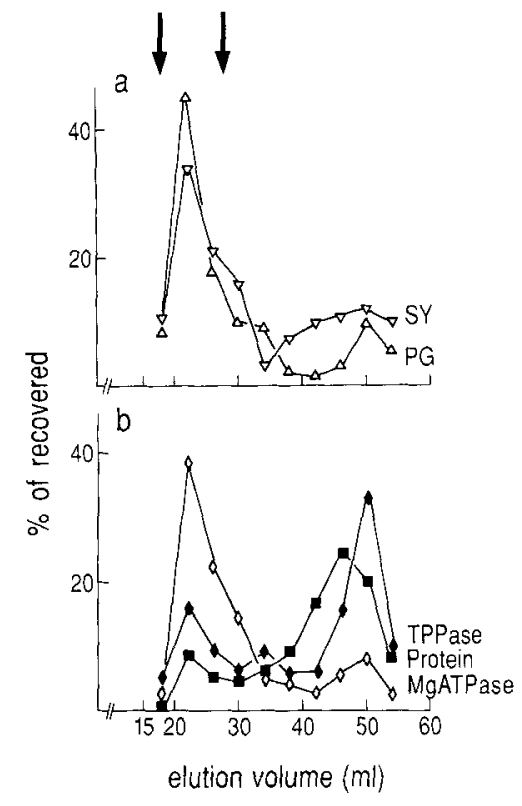

FIG. 5. Exclusion chromatography of particulate material in fraction $\mathrm{S}_{2}$ from electric lobes. Distribution in the eluate of a: Proteoglycan (triangles, PG) and synaptophysin (inverted triangles, SY). $\mathrm{b}: \mathrm{Mg}^{2+}$ dependent ATPase (open diamonds), TPPase (filled diamonds), and protein (filled squares). The arrows indicate the elution volumes of (left) chromaffin granules and (right) synaptic vesicles. It will be seen that a peak of $P G$ and $S Y$ of elution volume intermediate between that of chromatfin granules and synaptic vesicles and evidently corresponding to the VIPLI-containing particles is followed by a shoulder coincident with synaptic vesicles.

(Agoston and Conlon, 1986) to be localized in this tissue in the electromotor cell bodies, would be expected to behave similarly and this also (Table 5 , line 3 ) is what was found. The stable vesicle markers vesicle proteoglycan and synaptophysin (Table 5, lines 4 and 5) behave similarly. The cytoplasmic markers ChAT and $\mathrm{LDH}$ are also, as expected, mainly recovered in $\mathrm{S}_{2}$ (Table 5, lines 6-8) but the Golgi marker TPPase and the trimodally distributed $\mathrm{Mg}^{2+}$-dependent ATPase (Table 5, lines 9 and 10) show a more diffuse distri-

TABLE 5. Distribution of neuroactive substances, marker enzymes, and putative vesicle specific antigens in subcellular fractions of electric lobes of Torpedo

\begin{tabular}{|c|c|c|c|c|c|c|}
\hline \multirow[b]{2}{*}{ Component } & \multirow[b]{2}{*}{ Unit } & \multicolumn{4}{|c|}{ Distribution [units (g of tissue $)^{-1}$ ] } & \multirow{2}{*}{$\begin{array}{c}\text { Recovery } \\
(\%)\end{array}$} \\
\hline & & Homogenate & $\mathbf{P}_{1}$ & $\mathrm{P}_{2}$ & $\mathrm{~S}_{2}$ & \\
\hline Protein & $\mathrm{mg}$ & $68 \pm 5$ & $11.0 \pm 0.1$ & $25 \pm 2$ & $32 \pm 2$ & $98 \pm 4$ \\
\hline $\mathrm{ACh}$ & nmol & $25 \pm 2$ & $3.2 \pm 0.2$ & $3.2 \pm 0.2$ & $5.1 \pm 0.3$ & $88 \pm 4$ \\
\hline VIPLI & fmol-eq & $820 \pm 50$ & $120 \pm 16$ & $126 \pm 14$ & $418 \pm 51$ & $81 \pm 9$ \\
\hline PG & $\mathrm{dpm} 10^{-3}$ & $192 \pm 2$ & $29 \pm 3$ & $32 \pm 4$ & $72 \pm 8$ & $69 \pm 8$ \\
\hline SY & $\mathrm{dpm} 10^{-3}$ & $33 \pm 5$ & $4.4 \pm 0.5$ & $5.1 \pm 0.7$ & $15 \pm 2$ & $74 \pm 8$ \\
\hline ChAT & $\mathrm{nmol} \mathrm{h}^{-1}$ & $474 \pm 41$ & $56 \pm 4$ & $54 \pm 4$ & $396 \pm 32$ & $107 \pm 9$ \\
\hline $\mathrm{LDH}$ total & $\mathrm{mmol} \mathrm{h}^{-1}$ & $1.21 \pm 0.08$ & $0.31 \pm 0.03$ & $0.17 \pm 0.01$ & $0.83 \pm 0.05$ & $108 \pm 9$ \\
\hline LDH free & $\mathrm{mmol} \mathrm{h}^{-1}$ & $0.85 \pm 0.02$ & $0.08 \pm 0.00$ & $0.07 \pm 0.00$ & $0.81 \pm 0.07$ & $112 \pm 9$ \\
\hline MgATPase & $\mu \mathrm{mol} \mathrm{h}^{-1}$ & $135 \pm 11$ & $13.8 \pm 0.9$ & $55 \pm 4$ & $75 \pm 5$ & $107 \pm 9$ \\
\hline TPPase & $\mu \mathrm{mol} \mathrm{h}^{-1}$ & $5.4 \pm 0.4$ & $0.71 \pm 0.06$ & $2.2 \pm 0.2$ & $3.0 \pm 0.4$ & $109 \pm 9$ \\
\hline
\end{tabular}

Abbreviations as in Table 1. 
bution and considerably more activity in the $P_{2}$ fraction.

To examine whether fraction $S_{2}$ contained storage granules of the expected sizes, it was submitted to particle exclusion chromatography on columns calibrated with electromotor synaptic vesicles and chromaffin granules (Fig. 5). It will be seen that all three of the stable storage-granule and vesicle markers vesicular proteoglycan, synaptophysin, and $\mathrm{Mg}^{2+}$-dependent ATPase emerge as coincident sharp peaks with precisely the retention volume expected of a storage granule intermediate in size between chromaffin granules and electromotor synaptic vesicles. Shoulders on these peaks with a retention volume identical to that of electromotor synaptic vesicles indicated the presence of such vesicles also in the $S_{2}$ fraction. Unfortunately, the amounts of acetylcholine and VIPLI in fraction $S_{2}$ were so low that after the further, approximately 60 -fold dilution of fraction $S_{2}$ caused by elution through the column, the concentration of these neuroactive substances was too low for assay; it must be kept in mind that further considerable dilution is necessary before assay to reduce the sucrose and $\mathrm{NaCl}$ concentrations to acceptable values.

In the chromatography fractions, TPPase was mainly recovered in the soluble (nonexcluded) peak, though some had the same retention volume as the VIPLI peak. Possibly there is some contamination of the latter by small, vesiculated fragments of the Golgi membranes. Electromotor cell perikarya are rich in such membranes and their associated vesicles.

After separation by SDS-PAGE, the polypeptides of the proteoglycan- and synaptophysin-rich peak obtained from lobe fraction $S_{2}$ by exclusion chromatography again closely resembled those of the VIPLI-rich fractions of storage granules from nerve and organ. Similar components are also visible in electropherograms of $S_{2}$, together with others characteristic of synaptic vesicles against a background originating from soluble protein.

\section{DISCUSSION}

\section{Differences in the intracellular dynamics of neuropeptide- and acetylcholine-containing storage vesicles}

This article, together with a previous one (Agoston and Conlon, 1986), by demonstrating the presence of VIPLI in the "purely" cholinergic electromotor neurone, has extended the usefulness of the electromotor synapse as a cholinergic model system in which the functional significance of the colocalization of neuropeptides with classical neurotransmitters-in this case acetylcholine-can be studied. The results presented show that VIPLI is packaged separately from its cotransmitter in a storage granule distinct in density and morphology from the acetylcholine-sequestering synaptic vesicles. At the level of axonal transport, it is already a fully charged particle in contrast to the syn- aptic vesicles, which become fully charged only when they reach the terminal (Table 4). These differences clearly imply a difference in the intracellular dynamics of the two particles, similar to that recently observed in guinea-pig ileum (Agoston et al., 1988b), whereby the VIPLI-containing particles, like chromaffin granules and other cellular secretion vesicles, cannot be recycled in the cell's periphery whereas synaptic vesicles can be. It is, however, also clear that the two types of storage particles have several components in common; these include a proteoglycan of the heparan sulphate type originally found in electromotor synaptic vesicles (Stadler and Dowe, 1982; Walker et al., 1983), synaptophysin (Wiedenmann and Franke, 1985; Jahn et al., 1985), and $\mathrm{a} \mathrm{Mg}^{2+}$-dependent ATPase (Breer et al., 1977); the last two were also originally considered to be synaptic vesicle specific although synaptophysin had not previously been shown to be present in electromotor synaptic vesicles.

\section{Implications of results for the axonal transport of storage particles}

Previous work has shown that both vesicular proteoglycan (Jones et al., 1982; Agoston and Conlon, 1986; Kiene and Stadler, 1987) and VIPLI (Agoston and Conlon, 1986) are exported from the electromotor cell body to the terminal via the axon. The present work is consistent with this: it shows further that the VIPLI-containing granules isolated from the axons and the terminal are essentially identical and are responsible for part of the proteoglycan transported. The axonal and terminal populations of the synaptic vesicles also seem to be identical with respect to their proteoglycanto-synaptophysin ratio. Evidently the proteoglycan epitope recognized by our antiserum is unchanged by the arrival of the synaptic vesicle at the terminal and its maturation into a fully charged vesicle. This is in contrast to the results reported by Kiene and Stadler (1987) and Stadler and Kiene (1987), using a different serum, but would not preclude the loss, on maturation, of a (to our sera) nonimmunoreactive portion of the vesicular proteoglycan, such as part of its glucosaminoglycan, which is known to be readily detached by dialysis-induced hypoosmotic shock (Stadler and Dowe, 1982). By contrast, the axonal vesicles have a lower $\mathrm{Mg}^{2+}$-dependent ATPase, a lower density, and a much lower acetylcholine content than terminal vesicles. These parameters may be linked. The $\mathrm{Mg}^{2+}$-dependent ATPase, perhaps by generating a proton gradient across the vesicle membrane, may be part of the acetylcholine-uptake mechanism. Its down-regulation may be linked to the low acetylcholine content of the vesicles. If, in axonal synaptic vesicles, a relatively lighter inorganic cation (perhaps $\mathrm{K}^{+}$) largely replaces the heavier organic cation acetylcholine, the axonal vesicles may well be lighter than those in the terminal.

Kiene and Stadler (1987) also isolated a population (designated $\mathrm{VP}_{0}$ ) of low-density synaptic vesicles from the axon and demonstrated in pulse-labelling experi- 
ments that this population was also present in nerve terminals where it took up acetylcholine and, in some hours, acquired the density of replete $\left(\mathrm{VP}_{1}\right)$ synaptic vesicles (for review see Whittaker, 1987). Although Kiene and Stadler were unable to detect acetylcholine and ATP in their axonal vesicles, the presence of at least low concentrations seems to be required to explain the well-established finding that acetylcholine undergoes axonal transport in electromotor (Zimmermann and Whittaker, 1973; Heilbronn and Pettersson, 1973; Whittaker et al., 1975; Davies, 1978) and other cholinergic nerves (Dahlström et al., 1974) as does a stable fraction of ATP in electromotor nerves (Davies, 1978). The rate of transport is dependent on assumptions about the proportion being transported. If this is fairly low $(20 \%)$ the rate of accumulation of acetylcholine above a ligature is consistent with transport at the "fast" rate (Dahlström et al., 1974).

It is tempting to speculate that it is the exposure of axonal synaptic vesicles to the higher concentrations of cytoplasmic acetylcholine in the terminal that "unlocks" the uptake mechanism and promotes the filling of the newly arrived vesicles, with its attendant increase in vesicle density. A stimulating effect of acetylcholine (but not of choline) on the $\mathrm{Mg}^{2+}$-dependent ATPase of vesicles was indeed reported by Breer et al. (1977). Axonal synaptic vesicles may prove to be a useful tool for the investigation of such processes.

\section{Storage vesicles may have functional components in common}

Synaptophysin, vesicular proteoglycan, and $\mathrm{Mg}^{2+}$. dependent ATPase are now clearly emerging as common constituents of storage granules (Walker and Agoston, 1987). The functions of these common constituents are not yet fully understood. Synaptophysin may have a role in exocytosis (Buckley et al., 1987), the basic mechanism whereby storage particles of diverse function discharge their contents. Vesicular proteoglycan may serve to identify, and hold together as a unit, membranes of vesicular or granular origin during exocytosis and subsequent retrieval. The $\mathrm{Mg}^{2+}$-dependent ATPase and the proton translocation which it probably subserves may have acquired different functions in different types of storage particle during evolution. Thus, in our cholinergic model synapse, the acidification of the vesicle's interior which it may subserve in synaptic vesicles could drive the uptake of the acetylcholine cation whereas in VIPLI-containing vesicles it may activate the processing enzyme responsible for cleaving the precursor form of VIPLI observed in the electromotor axon (Agoston and Conlon, 1986).

Acknowledgment: We wish to express our gratitude to Herrn K. Seyfert of the Klinische Arbeitsgruppe für gastrointestinale Endokrinologie der Max-Planck-Gesellschaft for the VIPLI assays and to its Leiter, Dr. J. M. Conlon, for placing this service at our disposal. Dr. H. Stadler kindly provided the preparation of chromaffin granules. We are grateful to Drs. E. Floor, B. Wiedenmann, and R. Jahn for supplies of anti-synaptophysin antibodies and to Herrn J. W. Hell for discussions concerning the dot assays. D.V.A. was supported by the Deutsche Forschungsgemeinschaft (Grant no. Wh 1/4-2).

\section{REFERENCES}

Abercrombie M. (1946) Estimation of nuclear population from microtome sections. Anat. Rec. 94, 239-247.

Agoston D. V. (1987) Isolation and characterization of secretory granules storing a VIP-like peptide from the Torpedo electromotor system. (Abstr.) J. Neurochem. 48 (Suppl.), Si7ID.

Agoston D. V. and Conlon J. M. (1986) Presence of vasoactive intestinal polypeptide-like immunoreactivity in the cholinergic electromotor system of Torpedo marmorata. J. Neurochem. 47, $445-453$.

Agoston D. V., Kosh J. W., Lisziewicz J., and Whittaker V. P. (1985a) Separation of recycling and reserve synaptic vesicles from cholinergic nerve terminals of the myenteric plexus of guinea pig ileum. J. Neurochem. 44, 299-305.

Agoston D. V., Ballmann M., Conlon J. M., Dowe G. H. C., and Whittaker V. P. (1985b) Isolation of neuropeptide-containing vesicles from the guinea pig ileum. J. Neurochem. 45, 398-406.

Agoston D. V., Dowe G. H. C., Fiedler W., Giompres P. E., Roed I. S., Walker J. H., Whittaker V. P., and Yamaguchi T. (1986) A kinetic study of stimulus-induced vesicle recycling in electromotor nerve terminals using labile and stable vesicle markers. J. Neurochem. 47, 1584-1592.

Agoston D. V., Borroni E., and Richardson P. J. (1988a) Cholinergic surface antigen Chol- 1 is present in a subclass of VIP-containing rat cortical synaptosomes. J. Neurochem. 50, 1659-1662.

Agoston D. V., Conlon J. M., and Whittaker V. P. (1988b) Selective depletion of the acetylcholine and vasoactive intestinal polypeptide of the guinea-pig myenteric plexus by differential mobilization of distinct transmitter pools. Exp. Brain Res. 72, 535542.

Breer H., Morris S. J., and Whittaker V. P. (1977) Adenosine triphosphatase activity associated with purified cholinergic synaptic vesicles of Torpedo marmorata. Eur. J. Biochem. 80, 313-318.

Buckley K. M., Floor E., and Kelly R. B. (1987) Cloning and sequence analysis of $\mathrm{cDNA}$ encoding $\mathrm{p} 38$, a major synaptic vesicle protein. J. Cell Biol. 105, 2447-2456.

Dahlström A. B., Evans C. A. N., Häggendal C. J., Heiwall P.-O., and Saunders N. R. (1974) Rapid transport of acetylcholine proximal and distal to a lesion. J. Neural Transm. 35, 1-11.

Davies L. P. (1978) ATP in cholinergic nerves: evidence for the axonal transport of a stable pool. Exp. Brain Res. 33, 149-157.

Fahrenkrug J. (1985) Evidence for common precursors but differential processing of VIP and DHM in VIP-producing tumors. Peptides 6, 357-361.

Fonnum F. (1975) A rapid radiochemical method for the determination of choline acetyltransferase. $J$. Neurochem. 24, 407-409.

Giompres P. E., Morris S. J., and Whittaker V. P. (1981) The water spaces in cholinergic synaptic vesicles from Torpedo measured by changes in density induced by permeating substances. Neuroscience $4,757-763$.

Harios P., Lee D. A., and Stadler H. (1984) Characterization of a $\mathrm{Mg}^{2+}$-ATPase and a proton pump in cholinergic synaptic vesicles from the electric organ of Torpedo marmorata. Eur. J. Biochem. 144, 444-446.

Heilbronn E. and Pettersson H. (1973) Acetylcholine and related enzymes in normal and ligated cholinergic nerves from Torpedo marmorata. Acta Physiol. Scand. 88, 590.

Hell J. W. (1987) Eine neue Methode zur Isolierung synaptischer Vesikel aus Säugerhirn. Diplomarbeit, Universität Tübingen.

Jahn R., Schiebler W., Ouimet C., and Greengard P. (1985) A 38,000dalton membrane protein (p38) present in synaptic vesicles. Proc. Natl. Acad. Sci. USA 82, 4137-4141.

Johansson O. (1983) Localization of vasoactive intestinal polypeptideand avian pancreatic polypeptide-like immunoreactivity in the Golgi apparatus of peripheral neurons. Brain Res. 262, 71-78.

Johnson M. K. (1960) The intracellular distribution of glycolytic and other enzymes in rat brain homogenates and mitochondrial preparations. Biochem. J. 77, 610-618. 
Jones R. T., Walker J. H., Stadler H., and Whittaker V. P. (1982) Immunohistochemical localization of a synaptic-vesicle antigen in a cholinergic neuron under conditions of stimulation and rest. Cell Tissue Res. 223, 117-126.

Kiene M.-L. and Stadler H. (1987) Synaptic vesicles in electromotoneurones: 1. Axonal transport, site of transmitter uptake and processing of a core proteoglycan during maturation. EMBO J. 6, 2209-2217.

Laemmli U. K. (1970) Cleavage of structural proteins during the assembly of the head of bacteriophage T4. Nature 227, 680685 .

Lanzetta P. A., Alvarez L. J., Reinach P. S., and Candia O. A. (1979) An improved assay for nanomole amounts of inorganic phosphate. Anal. Biochem. 100, 95-97.

Ohsawa K., Dowe G. H. C., Morris S. J., and Whittaker V. P. (1979) The lipid and protein content of cholinergic synaptic vesicles from the electric organ of Torpedo marmorata purified to constant composition: implications for vesicle structure. Brain Res. 161, 447-457.

Peterson G. L. (1977) A simplification of the protein assay method of Lowry et al. which is more generally applicable. Anal. Biochem. 83, 346-356.

Smith A. D. and Winkler H. (1967) A simple method for the isolation of adrenal chromaffin granules on a large scale. Biochenn. J.103, 480-482.

Stadler H. and Dowe G. H. C. (1982) Identification of a heparan sulphate-containing proteoglycan as a specific core component of cholinergic synaptic vesicles from Torpedo marmorata. EMBO J. 1, $1381-1384$.

Stadler H. and Kiene M.-L. (1987) Synaptic vesicles in electromotoneurones: II. Heterogeneity of populations is expressed in uptake properties; exocytosis and insertion of a core proteoglycan into the extracellular matrix. EMBO J. 6, 2217-2221.

Stanley P. E. and Williams S. G. (1969) Use of liquid scintillation spectrometer for determining adenosine triphosphate by the luciferase enzyme. Anal. Biochem. 29, 381-392.

Tashiro T. and Stadler H. (1978) Chemical composition of cholinergic synaptic vesicles from Torpedo marmorata based on improved purification. Eur. J. Biochem. 90, 479-487.

Turner A. J., Hryszko J., Hooper N. M., and Dowdall M. J. (1987)
Purification and characterization of peptidyl dipeptidase resembling angiotensin converting enzyme from electric organ of Torpedo marmorata. J. Neurochem. 48, 910-916.

Walker J. H. and Agoston D. V. (1987) The synaptic vesicle and the cytoskeleton. Biochem. J. 247, 249-258.

Walker J. H., Obrocki J., and Zimmermann C. W. (1983) Identification of a proteoglycan antigen characteristic of cholinergic synaptic vesicles. $J$. Neurochem. 41, 209-216.

Whittaker V. P. (1984) The structure and function of cholinergic synaptic vesicles. Biochem. Soc. Trans. 12, 561-576.

Whittaker V. P. (1987) Cholinergic synaptic vesicles from the electromotor nerve terminals of Torpedo: composition and life cycle. Ann. NY Acad. Sci. 493, 77-91.

Whittaker V. P. and Barker L. A. (1972) The subcellular fractionation of brain tissue with special reference to the preparation of synaptosomes and their component organelles, in Methods of Neurochemistry, Vol. 2 (Fried R., ed), pp. 1-52. Marcel Dekker, New York.

Whittaker V. P. and Stadler H. (1980) The structure and function of cholinergic synaptic vesicles, in Proteins of the Nervous System, 2nd edit. (Bradshaw R. A. and Schneider D. M., eds), pp. 231255. Raven Press, New York.

Whittaker V. P., Essman W. B., and Dowe G. H. C. (1972) The isolation of pure cholinergic synaptic vesicles from the electric organs of elasmobranch fish of the family Torpedinidae. Biochem. J. 128, 833-846.

Whittaker V. P., Zimmermann H., and Dowdall M. J. (1975) The biochemistry of cholinergic synapses as exemplified by the electric organ of Torpedo. J. Neural Transm. Suppl. XII, 39-60.

Wiedenmann B. and Franke W. W. (1985) Identification and localization of an integral membrane glycoprotein of $\mathrm{M}_{\mathrm{r}} 38,000$ (synaptophysin) characteristic of presynaptic vesicles. Cell 41, 10171028.

Zimmermann H. and Denston C. R. (1977) Separation of synaptic vesicles of different functional states from the cholinergic synapses of the Torpedo electric organ. Neuroscience 2, 715-730.

Zimmermann H. and Whittaker V. P. (1973) Evidence for axonal flow of acetylcholine ( $\mathrm{ACh}$ ) in cholinergic nerves, in Abstracts of the Fourth International Meeting of the International Society for Neurochemistry, Tokyo, p. 245. 